\title{
A Study of College English Teaching Mode in the Context of Micro-learning
}

\author{
Qiong Fang \\ School of Foreign Languages, Anhui Sanlian University, Hefei 230601, China.
}

Keywords: micro-learning, college English, forgetting curve, language input.

\begin{abstract}
The development of mobile devices and the Internet has caused a dramatic change of humans learning mode. Along with the popularity and perfection of mobile handheld devices, a new learning mode, micro-learning has sprouted up among college students, which has become a challenge of college English teaching. To cope with this problem, English teachers should take advantage of the situation by making full use of micro-learning, including preview before class, classroom teaching and after-class practice, so as to strengthen the learning motivation of students and improve the effectiveness of teaching.
\end{abstract}

\section{Introduction}

The learning mode of humans is in the process of unprecedented change owing to the popularity of mobile devices and development of network communication. In the 21 st century, along with the exponential growth of knowledge and information, traditional "classroom + textbook" learning mode has failed to satisfy people's needs of seeking knowledge, and flexible, personalized learning modes gradually attracted the attention of people from all walks of life. A new type of learning mode, micro-learning, which is characterized by "smaller unit of study and shorter time focus", has become popular among college students [1]. Using mobile handheld devices (for example, a mobile phone), micro-learning concentrates on brief and independent messages. As there is no limit of time and space with micro-learning, it can provide college students with the information they need anywhere and anytime.

The application of handheld terminals has had a significant impact on college English teaching. Nowadays, as mobile phones are widely used in English class by students for looking up new words, translating sentences, or even finding answers to questions, many teachers complain about the use of cell phone as it might draw too much attention from the students and therefore interrupts the class. There are two distinct solutions to this problem: one is to strictly forbid students from using mobile phones or other handheld terminals in the class; another is try to take advantage of these devices to facilitate students' English learning.

Being brought up in information age, post-90 college students have been used to getting information and communicating with others by means of a smart phone, which is not just a tool for them to make phone calls and send text messages but also a convenient device to read news, watch videos, listen to music, among other things. A mobile phone has become an indispensable part of their life and study. However, relatively few attentions has been paid to the application of handheld devices in English learning. The author suggested that more research is needed into the ways in which college students use mobile phones and other handheld terminals in their English learning, in particular, their English micro-learning, which will facilitate the improvement of students' listening, speaking, reading and writing. In the meantime, their horizons will be expanded and ability be improved.

\section{Overview on Present Research Situation}

Micro-learning is also called bite-sized learning. Being a new mode of learning, it has attracted much attention in recent years. The prefix "micro-" has the meaning of "very small". Literally, when people do micro-learning, they deal with smaller learning units and the time they spent on learning is 
shorter than usual. Since micro-learning became popular in the twenty-first century with the appearance of new media, it has been a tremendous help to learners at different levels of the society [2]. An Austrian scholar Lindner (2004) first put forward the term "micro-learning", and after that research into it increased gradually throughout the world [3]. From 2005 to 2013, seven sessions of international conference on micro-learning were held in the University of Innsbruck, Austria, in which the application of micro-learning in various fields were studied and discussed. Being studied for more than a decade, micro-learning has gradually become a hot topic in learning science. In China, study in this field started in 2008. By searching China National Knowledge Infrastructure (CNKI), the author found out that the number of research papers on this topic rose steadily in the past decade. So far, its application has been extended to various fields, including foreign language learning [4].

\section{The Impact of Micro-learning on College English Teaching}

Along with the development of electronic products (including smart phones) and the universal use of the Internet, micro-learning has become a new type of learning mode and has played a significant role in the study and daily life of college students. In particular, it can provide the students with huge amount of personalized learning material, extend the time students spend on their language learning, and inspire their interest in learning. Therefore, research on its definition, feature, and other related issues should be carried out to facilitate the English learning of college students. The major impacts of micro-learning are listed as follows.

First of all, by means of handheld devices, students could be exposed to a round-the-clock English environment. Compared with the traditional foreign language teaching which was almost limited to classroom, this mode is obviously more convenient, more interesting and therefore more effective. From a psychological point of view, oblivion is inevitable in the process of acquiring new knowledge or skills. Memory and oblivion coexist with each other. Similar to all the other types of learning, when a student is learning a foreign language, the speed of his memory should be higher than his oblivion. And only in this way can he make progress with his language acquisition. According to the Ebbinghaus forgetting curve hypothesis, the process of forgetting is not linear but becomes slower and slower over time [5]. Students need to review in a timely manner in order to keep what they have learned in their memory. If the interval between two periods of learning is too long, the speed of forgetting might be greater than that of remembering. On this occasion, learning will become a failure. When we make a research into traditional English language teaching in China from this perspective, we find the reason why the teaching is not effective. For a long time, English teaching was mainly limited in classroom, which was almost the only opportunity for students to learning English. Outside class, some students rarely spent time on English, for lack of suitable learning material and environment. Currently, the number of English class hours in China's universities and colleges is quite small, and there is not enough time for students to learn English in the class, where language input mainly comes from the textbook and the teacher. English learning is unsatisfactory because of the long interval between two periods of English class. The wide use of smart phones and other handheld devices has dramatically changed the mode of English learning among college students. With the help of these devices, students will have more English resources to learn on their own. With a smart phone, a student can either watch English videos, listen to English songs or read whatever they are interest in. It's even possible for them to play video games in English. They can have fun and learn English at the same time. By using a smart phone, students are able to learn English whenever they want to. Using a smart phone, it is possible for them to review what they have learned in the class, to acquire personalized information, and to learn English on their own.

Secondly, micro-learning is not just helpful for the students to practice English language. It is also beneficial for them to acquire knowledge and information. In the past few decades, paper books have been faced with a serious challenge from the Internet, which has become the most convenient and therefore most common approach of reading for the students. However, the same knife cuts bread and fingers. Not all the messages on the Internet are good for young people and sometimes students are 
unable to distinguish between right and wrong. If the students follow their own inclination, inappropriate information might have a negative influence on them. In English class, the teacher should give proper guidance to the students, provide them with the learning resources that are appropriate for them. If classroom teaching is combined with extracurricular micro-learning, students will be exposed to English and achieve a huge amount of information. Nowadays, it is convenient to use a mobile phone to surf the Internet, and this makes it possible for students to get a vast amount of information relating to what they have learned in the class. In the meantime, they can also widen their horizon, keep track of the latest development of their own discipline and keep pace with the times. In addition, knowledge and information students acquired through micro-learning will exert a subtle influence on their outlook on life and core values.

Furthermore, when students are used to fragmented learning in English, it is likely that this mode will be gradually applied to the learning of other courses. As a result, their learning habits will be improved and learning strategies be optimized. English is one of the most important courses in colleges and universities in China with more class hours than average. There is no doubt that the learning mode of students is closely related to the effectiveness of their English learning. Besides, it also has an effect on learning strategies and motivation of the students, which will influence the teaching effectiveness of other courses indirectly. Therefore, special attention ought to be paid to the development of students' English micro-learning, to facilitate the development of students in many aspects, at various levels.

\section{The Application of Micro-learning in College English Teaching}

Since micro-learning is popular with college students, enough attention should be paid to it. If we ignore it, students might use it in an inappropriately way. On the contrary, if an English teacher makes an intensive study of its mode, contents, and try to be involved in the students' micro-learning by giving them advice and assistance, the result will be much better. There are always plenty of articles, videos, and other forms of messages on the Internet for the students to learn and imitate. In addition, it is also workable for the teacher to offer students specific learning materials online that are suitable for them. With a smart phone, students can get access to English whenever they want, wherever they go. This means that micro-learning is useful throughout the whole process of college English teaching. In this paper, study is carried out at three stages: before-class preview, classroom activities, and after-class learning.

\subsection{Before-Class Preview.}

Whether an English class is successful or not depends largely on how well the students have been ready for it. For Chinese college students, their problems of learning English are not just the language itself, but also knowledge and information about English speaking nations, including their society, politics, economy and culture. It's unlikely to provide the students with all the related information in the class. Assigning the students to preview beforehand will lead to a more effective classroom teaching. Teaching practice shows that when a teacher highly values before-class preview, and gives clear and detailed instructions on what and how to do, learning is more effective. As for English class, the following activities are good.

Classroom presentation. In order to present in the class, students are required to surf the Internet before class. Students have to collect a large amount of information through the Internet, and make a speech in the class on the basis of their comprehension of the background knowledge. These activities are helpful for the students to improve their skimming, scanning, and oral language. Their ability to get information will also be enhanced.

Written statement. Students are required to hand in an essay with a title given by the teacher before class. Similar to the previous one, in order to finish this exercise, the students also need to read extensively and write a summary on their own. Difference between the two: the former focuses on spoken language while the latter on written language. 
Classroom discussion. A topic is set for students to discuss in the next class. To do this, students have to get ready for it before class in several possible ways. For example, students in a class can be divided into groups. Inside a group, the students have different tasks like collecting information, deciding an argument, selecting supporting materials and so on. They cooperate with each other in order to win. In this process, their abilities to collect information, think critically, and their reading comprehension, spoken language as well as cooperation will be enhanced.

\subsection{Classroom Activities.}

A smart phone can be very useful in the class. In the past few years, along with the popularity of smart phones, there are more and more smart phone addicts in English class. In some universities, the use of smart phones is forbidden in the class to avoid its disturbance. The author believes that it is not the best choice to prohibit the use of smart phone in English class. Instead, efforts ought to be made to help the students to make good use of mobile phones in their English learning, including classroom learning, so as to compensate for the deficiencies in traditional language teaching. At present, there are usually two major problems with college English teaching in China. First, students in a class are from various areas and high schools of the country, with their English basis vary from each other. Second, in some cases, an English class contains a large number of students. As a result, it is difficult for the teacher to pay enough attention to the demands of individual students.

With the help of smart phones, classroom teaching can be combined with personalized autonomous learning. Take vocabulary teaching as an example. In a class, some students may have a wider vocabulary than average while some others can only recognize a few words. It's almost impossible for the teacher to find the balance between the two extremes. If the use of smart phone is encouraged in the class, and a couple of minutes is set for the students to consult a dictionary online, students will get whatever they want on their own. This method is especially suitable for those who are faced with more challenges in their English, with a relatively limited vocabulary. Under the instructions of the teacher, this group of students can spend more time after class to compensate for their own deficiencies and catch up with other classmates gradually. With the help of smart phone, time spent on teaching new words and phrases can be shortened by a large margin. This makes the teaching more effective.

\subsection{After-Class Exercise.}

Presently, the Internet plays an indispensable role in doing after-class exercises. Many English teachers tend to select the assignments give on the textbook. A few decades ago, students used to spend a long period of time to finish them. However, things have changed dramatically since the advent of Internet. Some students even search the Internet for the keys directly. It turns out that this kind of exercise is of little avail.

Homework should be given in consideration of characteristics of the times and learning mode of the students. The question-and-answer drills with their keys available online should be avoided. Instead, the use of handheld devices will be taken in account while giving students assignments, to facilitate their independent learning. For example, listening practice can be carried out after class, when students listen to the record and repeat after it on their own. They can also take dictation. Another possible exercise is to ask the students to listen to a dialogue repeatedly before class, and ask them to perform role play in the class on the basis of what they have listened beforehand. Besides, it is advisable for teachers to make up exercises that are fit for the students, with their keys unavailable online. In this way, students have to study independently and finish them autonomously.

\section{Summary}

Handheld devices and the Internet is a double-edged sword in English teaching. If we take full advantage of it, micro-learning can be beneficial to college English teaching in that it tackles the problems of limited class hours, too many students in a class, and various requirements of the students. One of the advantages of micro-learning is that it provides the students with huge amount of English input. Based on this, through well-designed classroom teaching, students will be able to develop their 
language output competence accordingly. Micro-learning has the features of constant repetition, fragmentation and individuation. When this mode is adopted by college students, their learning motivation will be greatly aroused, their time spent on autonomous learning be extended and horizon broadened. In this process, students' English vocabulary, grammar and their knowledge of English speaking countries will be improved. All these will finally lead to the improvement of their comprehensive capacity.

\section{Acknowledgments}

This research is financially supported by the Quality Engineering Program of Anhui Higher Education (2015tszy035), Quality Engineering Program of Anhui Sanlian University (17zlgc029), and Key Research Program of Humanities and Social Science of Anhui Education Department (SK2016A0341).

\section{References}

[1]. Hongzhen Zuo, Jiawei Han, Yanyang Jia. The Application of Micro-learning Design in English Teaching from the Perspective of Handheld Terminals. China Educational Technique \& Equipment. Vol. 26 (2013) No.36, p.17-18.

[2]. Zhiting Zhu, Hao Zhang, Xiaoqing Gu. Micro-learning-Practical Mode of Informal Learning. China Educational Technology. Vol. 28 (2008) No.2, p.10-13.

[3]. Jun Wu. Exploration and Practice of Micro-learning in Teaching. Computer Age. Vol. 30 (2013) No.7, p. 55-56.

[4]. Zhenhong Zhang, Qingying Yang, Zhi Han. A Study on Micro-learning: Current Situation and Future. China Educational Technology. Vol. 33 (2013) No.11, p. 13-20.

[5]. Hongli Wang. A Magic Weapon of Memory: Fantastic Imagery Memory and the Development of Supernormal Rapid Memory. China Youth Publishing House. 2004, p.27. 